\title{
Pain-related cerebral activation is altered by a distracting cognitive task
}

\author{
P. Petrovic, K.M. Petersson, P.H. Ghatan, S. Stone-Elander, M. Ingvar* \\ Section of Clinical Neurophysiology, Department of Clinical Neuroscience, Karolinska Institute/Karolinska Hospital, 17176 Stockholm, Sweden
}

Received 5 January 1999; received in revised form 2 September 1999; accepted 22 September 1999

\begin{abstract}
It has previously been suggested that the activity in sensory regions of the brain can be modulated by attentional mechanisms during parallel cognitive processing. To investigate whether such attention-related modulations are present in the processing of pain, the regional cerebral blood flow was measured using $\left[{ }^{15} \mathrm{O}\right]$ butanol and positron emission tomography in conditions involving both pain and parallel cognitive demands. The painful stimulus consisted of the standard cold pressor test and the cognitive task was a computerised perceptual maze test. The activations during the maze test reproduced findings in previous studies of the same cognitive task. The cold pressor test evoked significant activity in the contralateral S1, and bilaterally in the somatosensory association areas (including S2), the ACC and the mid-insula. The activity in the somatosensory association areas and periaqueductal gray/midbrain were significantly modified, i.e. relatively decreased, when the subjects also were performing the maze task. The altered activity was accompanied with significantly lower ratings of pain during the cognitive task. In contrast, lateral orbitofrontal regions showed a relative increase of activity during pain combined with the maze task as compared to only pain, which suggests the possibility of the involvement of frontal cortex in modulation of regions processing pain. (C) 2000 International Association for the Study of Pain. Published by Elsevier Science B.V. All rights reserved.
\end{abstract}

Keywords: Pain; Positron emission tomography; Regional cerebral blood flow; Cognition; Distractor; Periaqueductal gray; Secondary somatosensory area; Tonic pain; Cold pressor test

\section{Introduction}

Pain is a complex sensation involving sensory-discriminative, affective-motivational and cognitive-evaluative aspects (Melzack and Casey, 1968). The sensory-discriminative and affective-motivational components have been thoroughly studied in previous functional imaging experiments (Jones et al., 1991; Talbot et al., 1991; Coghill et al., 1994; Apkarian, 1995; Casey et al., 1996; Vogt et al., 1996; Andersson et al., 1997; Davis et al., 1997; Derbyshire et al., 1997; Rainville et al., 1997). Here, we report a study focusing on the cognitive-evaluative dimension in pain perception during a concurrent attention-demanding task.

Active attentional modulation of task-irrelevant input has previously been shown in and between other sensory modalities (Rees et al., 1997; Ghatan et al., 1998). Higher-order cognitive regions may mediate such modulations by feedback loops to primary sensory and association regions (Mesulam, 1998). Such systems should be crucial also in pain-networks which would be in line with behavioural studies showing that the affective-motivational and the sensory-discriminative aspects of pain may be blocked by

\footnotetext{
* Corresponding author. Tel.: +46-8-5177-5134; fax: +46-8-344-146.

E-mail address: martini@neuro.ks.se (M. Ingvar)
}

'excitement in games or war' (Melzack and Casey, 1968). It has also been shown that pain ratings during cold pressor test may be significantly reduced during the first minute when a cognitive task is solved simultaneously (Hodes et al., 1990). The pain modulation may be exerted both directly on regions processing noxious input in the brain and indirectly by changing the input of nociceptive signals from the periphery. It has been suggested that the prefrontal cortex may play a significant role in pain modulation during cognitive activities since it receives intracortical information from most cortical sensory and association areas and projects to reticular and limbic structures (Melzack and Casey, 1968). Indeed, studies involving electric stimulation of orbitofrontal and medial prefrontal cortex have shown analgesic effects in primates and non-primates (Oleson et al., 1980; Hardy, 1985; Zhang et al., 1997).

Based on these findings we hypothesised that a relative decreased activity should be observed in pain processing regions, that is the contralateral primary somatosensory cortex (S1) with the somatotopic region for the hand, somatosensory association areas including the human homologue for S2, the insula and the ACC during pain induced simultaneously with a concurrent attention demanding task than during pain per se. It was also hypothesised that the activity 
in the orbitofrontal cortex and the medial prefrontal cortex would increase relatively during pain combined with distraction as compared to pain per se, because of their suggested involvement in modulation of pain-related activity in the brain.

The first minute of the cold pressor test was used to induce the painful experience since quantitative EEG has suggested later inhibitory processes (indicated by elevated alpha power) in central and parietal regions during cold pressor stimulation (Backonja et al., 1991). To induce an attention, working memory, and on-line executive demanding cognitive load a computerised perceptual maze test (Maze) was used, as previously described in a functional imaging study (Ghatan et al., 1995). A high level of attention is required in order to perform the on-line task.

\section{Materials and methods}

\subsection{Experimental design}

The computerised maze test used here is a slightly modified version of the APT (Automated Psychological Testbattery) software package (Levander, 1988; Ghatan et al., 1995). In the maze test the subjects had to continuously solve an on-line visual-spatial task presented on a monitor in front of them. The task was to connect a number of target dots, superimposed on the intersections of a background grid, by pressing two keys with their right hand and find a path along the grid that passes through the greatest number of target dots (Fig. 2A). The complexity of the maze task is based on the number of rows, saturation (defined as the proportion of nodes that are marked with a target), and a pattern factor (Elithorn, 1964; Smith et al., 1978). The subjects made scores for each correctly solved task. When a subject had correctly solved a maze, the next one presented was of higher complexity until the highest possible complexibility was reached (as limited by the dimensions of the computer screen). Solving a more complex task yielded higher scores. Since a new maze was presented immediately following the solved maze, faster correct solutions improved the result. If the subject did not solve a maze correctly the next one displayed was less complex. The subjects were told to concentrate on the maze task and try to improve their score every time they solved a new maze. In order to minimise learning related effects and stabilise performance all subjects went through a practice session, at least 3 days before the scanning procedure. This session included maze practice and the same Cold/Maze, Pain/ Maze and Pain conditions as during the scanning session (three of each condition). The procedure was also rehearsed during the transmission scan.

Twelve repeated measurements of the regional cerebral blood flow (rCBF) were made in each subject using a 3D Ecat Exact HR positron emission tomograph (PET) and bolus injections of $500 \mathrm{MBq}\left[{ }^{15} \mathrm{O}\right]$ butanol (Berridge et al.,
1990; Ingvar et al., 1994; Wienhard et al., 1994). The time from the tracer injection to the arrival of the bolus to the head was approximately $15 \mathrm{~s}$ and was followed by a 1-min tracer up-take scan. Individual plaster head support was made for each subject to minimise head movements during the PET imaging (Bergström et al., 1981). rCBF was measured in four different conditions:

1. Pain (P); Left hand immersed in circulating water with a temperature of $0-0.5^{\circ} \mathrm{C}$ (standard cold pressor test) starting immediately after the tracer-injection and continuing to the end of the scanning period. Subjects had the instruction to fixate on a hair-cross on the screen in front of them starting $30 \mathrm{~s}$ before the tracer-injection;

2. Cold (C); As above, but the left hand was immersed in circulating water with a temperature of $19 \pm 0.5^{\circ} \mathrm{C}$;

3. Pain/Maze $(\mathrm{P} / \mathrm{M})$; The subjects were engaged in the externally driven perceptual maze task starting $30 \mathrm{~s}$ before the tracer-injection and continuing to the end of the scanning period with the left hand immersed in 0 $0.5^{\circ} \mathrm{C}$ water (standard cold pressor test) as above;

4. Cold/Maze (C/M); Same as $3(\mathrm{P} / \mathrm{M})$ but with a water temperature of $19 \pm 0.5^{\circ} \mathrm{C}$.

Thus, a factorial experimental design was used with the factors cognitive and sensory state (Fig. 1). The twelve scans were pseudorandomized; that is one of each condition was randomly included in every group of four scans. Thus, all of the three sub-groups of scans contained condition 1 to 4. The subjects were told to avoid movements except for the movements required to solve the perceptual maze task. The subjects were informed before each scan about the new condition. The inter-scan interval was 10-12 min allowing for the radioactivity of the subject to return to baseline. After each scanning the subjects rated the pain intensity and the pain unpleasantness using a $10-\mathrm{cm}$ long sliding mechanical visual analogue scale. $0 \mathrm{~mm}$ equalled no pain

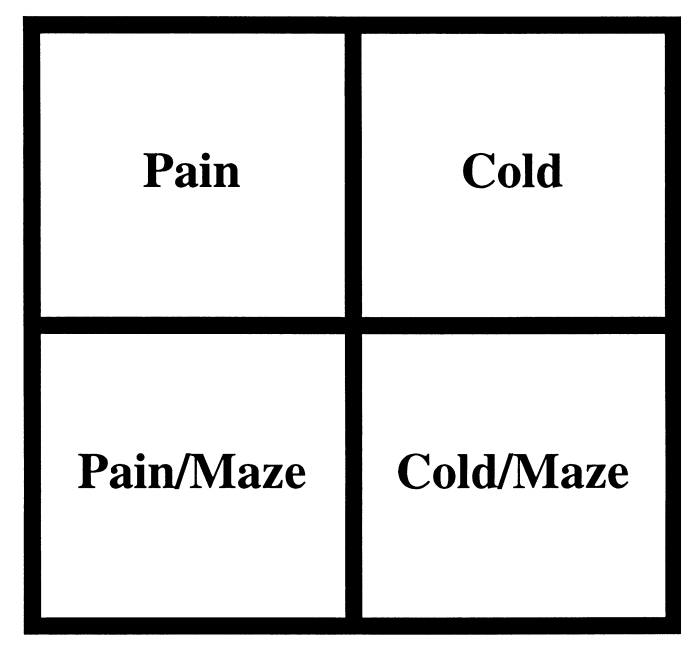

Fig. 1. The four states that were studied and allowed an interaction analysis of ((Pain - Cold $)$ - (Pain/Maze - Cold/Maze $))$ and ((Pain/Maze - Cold/ Maze) - (Pain - Cold $)$. 
A

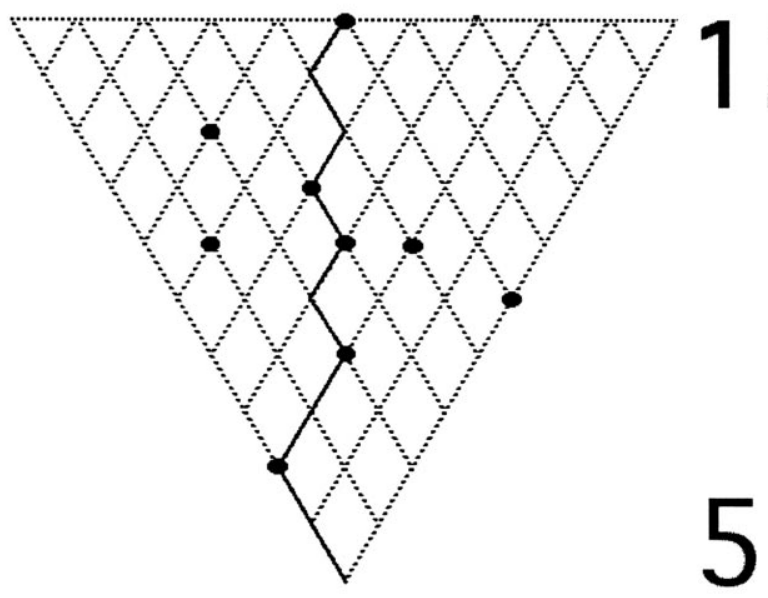

B

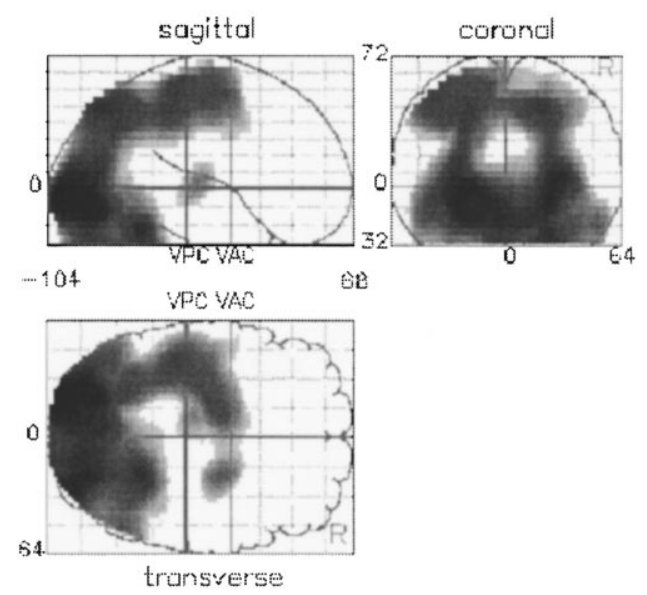

Fig. 2. The triangular maze used in the maze task (A). The image contains a grid with superimposed dots, a digit indicating the maximal number of dots that can be targeted in each maze and the total score. While solving the task the subject obtains visual feedback indicating the route that has been chosen during advancement from the bottom to the top of the maze. Main effect of the increases in rCBF during the Maze task (B). Data are given as a statistical parametric map (SPM) thresholded at $Z=3.09$ and displayed in a standard format as a maximum intensity projection view.

intensity/unpleasantness at all and $100 \mathrm{~mm}$ equalled the highest imaginable pain intensity/unpleasantness. The subjects were also asked if the pain intensity/unpleasantness was equal, less or higher during $\mathrm{P} / \mathrm{M}$ as compared to $\mathrm{P}$ after each of the three sub-groups of scans was completed (each sub-group containing one of each condition).

\subsection{Data-analysis and statistics}

Of the ten subjects included in the study (males, righthanded, 20-35 years) three were uncomfortable with the head fixation during the scanning-session. They complained that aching from the head fixation was a major distractor and rated the pain intensity/unpleasantness up to $45 / 100$ on the same VAS used in the study. Because this may have interfered with the experimentally induced activity these subjects were excluded from further analysis.

The PET images were realigned, spatially normalised, 3D Gaussian filtered (FWHM $=16 \mathrm{~mm}$ ) and modeled with the general linear model using the SPM95 software (Friston et al., 1995). The PET data were proportionally scaled in order to account global confounders (e.g. variations in injected radioactive dose) and the global CBF-activity was set to (arbitrary) 50 units $/ 100 \mathrm{~g} / \mathrm{min}$. Four conditions and seven blocks (subjects) were included in the general linear model resulting in 62 residual degrees of freedom ( 84 scans) for the group analysis.

First, the rCBF increases and decreases were studied in regions of a predefined matrix, for pain with or without maze task $((\mathrm{P}-\mathrm{C})$ and $(\mathrm{P} / \mathrm{M}-\mathrm{C} / \mathrm{M}))$, and for the main effect of pain $((\mathrm{P}+\mathrm{P} / \mathrm{M})-(\mathrm{C}+\mathrm{C} / \mathrm{M}))$. The $\mathrm{rCBF}$ changes were also studied for the separate maze contrasts $((\mathrm{C} / \mathrm{M}-\mathrm{C})$ and $(\mathrm{P} / \mathrm{M}-\mathrm{P}))$ and for the main effect of maze $((\mathrm{P} / \mathrm{M}+\mathrm{C} / \mathrm{M})-(\mathrm{P}+\mathrm{C}))$. Also, the interaction analysis of $((\mathrm{P}-\mathrm{C})-(\mathrm{P} / \mathrm{M}-\mathrm{C} / \mathrm{M}))$ and $((\mathrm{P} / \mathrm{M}-\mathrm{C} /$ $\mathrm{M})-(\mathrm{P}-\mathrm{C}))$ were performed (Fig. 1) in relation to the predefined matrix. The subject-specific mode was used and the scanning orders were set as confounding covariate to account for individual variability of the pain experience and linear time effects.

The predefined matrix was chosen based on previous functional neuroimaging studies of experimental pain (Jones et al., 1991; Talbot et al., 1991; Casey et al., 1994, 1996; Hsieh et al., 1995a; Coghill et al., 1994; Craig et al., 1996; Vogt et al., 1996; Adler et al., 1997; Andersson et al., 1997; Derbyshire et al., 1997; Gyulai et al., 1997; Rainville et al., 1997; Xu et al., 1997; Iadarola et al., 1998). However, activations in areas of BA43 and inferior parts of BA40 (BA40i) are referred to as activations in somatosensory association areas rather than secondary sensory cortex (S2) although they probably include the human homologue of S2 (see Section 4). The orbitofrontal cortex (here defined as BA47/BA11/BA25) and ventromedial prefrontal cortex (here defined as BA9/BA10 of medial frontal gyrus) are also known to be crucial in modulation of pain processing and affective-autonomic processing and were therefore also expected to be involved in attentional modulation of pain (Oleson et al., 1980; Hardy, 1985; Zhang et al., 1997). Thus, the regions included in the matrix were the contralateral primary somatosensory cortex (S1), and, bilaterally, the secondary association areas, the mid-/anterior insula, the anterior cingulate cortex (ACC), the periaqueductal gray (PAG)/midbrain, the orbitofrontal cortex and the ventromedial prefrontal cortex. All rCBF changes detected in the predefined regions with an uncorrected $P$-value $<0.05$ were included in the presentation of the results. Increased activity in this matrix with a $Z$-score $>3.09(P<0.001)$ was regarded as significant. Coordinates and anatomical 
definitions of local maxima are given according to an approximate Talairach-Tournoux stereotactical space (Talairach and Tournoux, 1988).

To reduce the search volume and increase the sensitivity of the interaction analysis a masking procedure of the interaction contrast was performed with the relevant contrasts. This procedure also assures that observed interactions were in the functionally defined matrix activated by just pain or by pain during the maze task. The initial threshold was set to $Z=2.33$ and clusters of volume $\geq 10$ voxels with a maxima with $Z$-score $>2.56(P \leq 0.005)$ were accepted as significant for the predefined regions. Thus $[(\mathrm{P}-\mathrm{C})-(\mathrm{P} / \mathrm{M}-\mathrm{C} /$ $\mathrm{M})$ ] was masked by the $(\mathrm{P}-\mathrm{C})$-matrix and $[(\mathrm{P} / \mathrm{M}-\mathrm{C} / \mathrm{M})-$ $(\mathrm{P}-\mathrm{C})$ ] was masked by the $(\mathrm{P} / \mathrm{M}-\mathrm{C} / \mathrm{M})$-matrix. Only those predefined regions in the interaction analysis, which were significant after masking procedure are reported.

\section{Results}

\subsection{Behavioural results}

The subjects were able to perform the maze task during the pain provocation and the scores were not statistically different between the $\mathrm{P} / \mathrm{M}$ and $\mathrm{C} / \mathrm{M}$ conditions (the mean score during the $\mathrm{P} / \mathrm{M}$ was $249(\mathrm{SD}=58.8)$ and the mean score during $\mathrm{C} / \mathrm{M}$ was $243(\mathrm{SD}=51.0) ; P$-value $=0.60$; paired $t$-test on the average scores; $\mathrm{df}=6$ ).

The subjective rating of the pain intensity and unpleasantness by the VAS was reduced during the P/M as compared to the $\mathrm{P}$ condition. The average rating of the pain intensity was $27.7 \mathrm{~mm} \quad(\mathrm{SD}=17.3)$ during $\mathrm{P}$ and $21.4 \mathrm{~mm}$ $(\mathrm{SD}=17.2$ ) during $\mathrm{P} / \mathrm{M}$ and the average rating of the pain unpleasantness was $25.6 \mathrm{~mm}(\mathrm{SD}=15.3)$ during $\mathrm{P}$ and $18.8 \mathrm{~mm}(\mathrm{SD}=15.0)$ during $\mathrm{P} / \mathrm{M}$. The difference in the ratings between the $\mathrm{P}$ and $\mathrm{P} / \mathrm{M}$ was significant with a $P$-value $<0.002$ for the pain intensity and a $P$-value $<0.019$ for pain unpleasantness (paired $t$-test on each subjects aver- age VAS scores; df $=6$ ). The subjects also consistently stated that the pain intensity and pain unpleasantness was felt less during $\mathrm{P} / \mathrm{M}$ than during $\mathrm{P}$ after each sub-group of four scans.

\subsection{PET results}

\subsubsection{Maze-test}

In the main effect condition for the perceptual maze $[(\mathrm{P} / \mathrm{M}+\mathrm{C} / \mathrm{M})-(\mathrm{P}+\mathrm{C})]$ increased activity was observed bilaterally in vast regions of the occipital cortex, posterior parietal cortex, posterior temporal cortex, cerebellum and in the left sensorimotor cortex (Fig. 2B). Extensive deactivations were observed in vast regions of frontal cortex, mid temporal cortex, anterior temporal cortex, cingulate cortex and left sensorimotor gyrus/inferior parietal gyrus. Due to limitations in space and since the main effect generally replicates previous PET-studies of the maze task (Ghatan et al., 1995; Ingvar et al., 1998), the voxel maxima for these activations are not presented here (the data is available upon request). A similar pattern of activations and deactivations were observed in the simple main effects of maze $(\mathrm{P} / \mathrm{M}-\mathrm{P}$ and $\mathrm{C} / \mathrm{M}-\mathrm{C}$ ).

\subsubsection{Pain}

In the grouped pain conditions $[(\mathrm{P} / \mathrm{M}+\mathrm{P})-(\mathrm{C} / \mathrm{M}+\mathrm{C})]$ significant activations were observed in the contralateral $\mathrm{S} 1$, the contralateral somatosensory association areas (including $\mathrm{S} 2$ ), the ACC and the mid-/anterior insula bilaterally (Table 1; the $\mathrm{rCBF}$ for $\mathrm{ACC}$ and mid-/anterior insula are shown in Fig. 3). Also, an ipsilateral activation in the somatosensory association regions was observed. No activations were observed in the orbitofrontal or ventromedial prefrontal regions and no decreases were observed in the predefined regions.

The same pattern of activation, as in the main effect analysis of pain, was disclosed in the $(\mathrm{P}-\mathrm{C})$ condition. However, although S1 and the somatosensory association

Table 1

Results of the main effects of pain ${ }^{\mathrm{a}}$

\begin{tabular}{|c|c|c|c|}
\hline & $X Y Z$-coordinates & Z-score & $\Delta-\mathrm{rCBF}(\%)$ \\
\hline \multicolumn{4}{|l|}{$[(\mathrm{P}+\mathrm{P} / \mathrm{M})-(\mathrm{C}+\mathrm{C} / \mathrm{M})]$} \\
\hline $\mathrm{S} 1 \mathrm{dx}$ & $44-2848$ & $5.20 \mathrm{~S}$ & 4.20 \\
\hline Sensory association regions $\mathrm{dx}$ & $40-1816$ & $4.27 \mathrm{~S}$ & 2.12 \\
\hline Sensory association regions sin & $-60-816$ & $3.12 \mathrm{~S}$ & 1.47 \\
\hline \multirow[t]{3}{*}{$\mathrm{ACC}(\mathrm{BA} 32 / 24)$} & $14 \quad 1024$ & $3.59 \mathrm{~S}$ & 1.94 \\
\hline & $-10 \quad 2420$ & 3.01 & 2.10 \\
\hline & $-10-232$ & 2.98 & 1.68 \\
\hline Mid-/anterior insula $\mathrm{dx}$ & $36-1212$ & $4.28 \mathrm{~S}$ & 1.92 \\
\hline Mid-/anterior insula sin & $\begin{array}{lll}-38 & -4 & 0\end{array}$ & $3.51 \mathrm{~S}$ & 1.39 \\
\hline PAG/midbrain & $2-24 \quad 0$ & 2.09 & 0.83 \\
\hline Orbitofrontal cortex & - & - & - \\
\hline Ventromedial prefrontal cortex & - & - & - \\
\hline
\end{tabular}

\footnotetext{
${ }^{a}$ The search volume was restricted to the a priory defined pain matrix. The locations are given in the coordinates of the Talairach-Tournoux atlas (Talairach and Tournoux, 1988). S, significant activation; Sin, sinister (left); dx, Dexter (right). A negative $x$ coordinate denotes that the activation is in the left hemisphere and positive $x$ coordinate denotes the activation is in the right hemisphere. The presented XYZ-coordinates refer to the most significant voxel.
} 
areas (including S2), were clearly activated (Fig. 4A-C and Fig. 5A) no activation above significance was observed in the ACC (peak activations: $-10-236, Z=2.51$; and 12 $1224, Z=2.45$ ) or mid-/anterior insula. As above, no activations were observed in the orbitofrontal or ventromedial prefrontal regions and no decreases were observed in the predefined regions.

In the $(\mathrm{P} / \mathrm{M}-\mathrm{C} / \mathrm{M})$ condition $\mathrm{ACC}$ showed activations below or just above the significance level (peak activations: $181024, Z=3.13$; $-143220, Z=2.87$; and $-12-232$, $Z=1.99$ ). A significant activation was disclosed in the left orbitofrontal region (Fig. 4D). Several other sites in the left and right orbitofrontal regions, and in the ventromedial prefrontal cortex showed subsignificant rCBF increases. No significant activation was observed in left S1 for the hand, the sensory association areas or in the mid-/anterior insula (Fig. 5B). No decreases were observed in the predefined regions.

\subsubsection{Analysis of interaction}

The interaction analysis $[(\mathrm{P}-\mathrm{C})-(\mathrm{P} / \mathrm{M}-\mathrm{C} / \mathrm{M})]$ masked with the contrast $(\mathrm{P}-\mathrm{C})$ showed a significant interaction in the right BA43 of the somatosensory association areas (Figs. $4 \mathrm{E}$ and $5 \mathrm{C}$ ). In the left hemisphere there was a similar significant interaction after the same masking procedure (Figs. 4F and 5C). However, it was some-what more superior with the maximum between BA43, BA40 and S1. The PAG/midbrain also showed a significant interaction after the same masking procedure (Fig. 4G). The interaction activity for the hand region of $\mathrm{S} 1$ did not reach significance.

After masking $[(\mathrm{P} / \mathrm{M}-\mathrm{C} / \mathrm{M})-(\mathrm{P}-\mathrm{C})]$ with the contrast $(\mathrm{P} / \mathrm{M}-\mathrm{C} / \mathrm{M})$ significant interactions were observed in the lateral orbitofrontal cortex (BA47 in the right hemisphere and BA47 in the left hemisphere; Figs. 4H,I and 5D).

\section{Discussion}

\subsection{General findings}

This study revealed $\mathrm{rCBF}$ interactions between a cognitive task and pain stimulation, which indicate a possible functional change pertaining to the lowered perception of pain during distraction. Pain evoked activations were significantly lowered in the somatosensory association areas (including S2) and PAG/midbrain when the subjects also were performing the maze task, while the activity was relatively increased in lateral orbitofrontal regions.

We have chosen to designate activations in the BA43 and BA40 of the inferior parietal lobe as pertaining to somatosensory association areas since several regions around the lateral sulcus are involved in somatotactile and pain-processing. The secondary somatosensory cortex (S2) has been defined anatomically in the dorsal bank of the lateral sulcus in the parietal operculum of the monkey (Roberts and Akert, 1963) and is involved in processing of nociceptive signals (Robinson and Burton, 1980; Dong et al., 1989). Recent studies have disclosed that this area actually consists of two different regions in primates, with their own representation of the body surface (termed S2 and the parietal ventral area; Krubitzer et al., 1995). Posterior insula, also involved in the pain experience, is situated immediately medial to S2 on the medial surface of the lateral sulcus (Mesulam and Mufson, 1985). Area 7b is located posterior-lateral of S2 in primates and contains more neurons, which respond to nociception than S2 (Robinson and Burton, 1980). Also, a small area called retroinsula that is implicated in somatotactile processing is situated posteriorly of insula and S2 (Robinson and Burton, 1980). Since these areas are situated anatomically very close, involved in somatosensory processing and intimately connected, a clear separation is not possible in human PET-studies. Moreover, a clear separation between these areas has not been done in humans although it seems
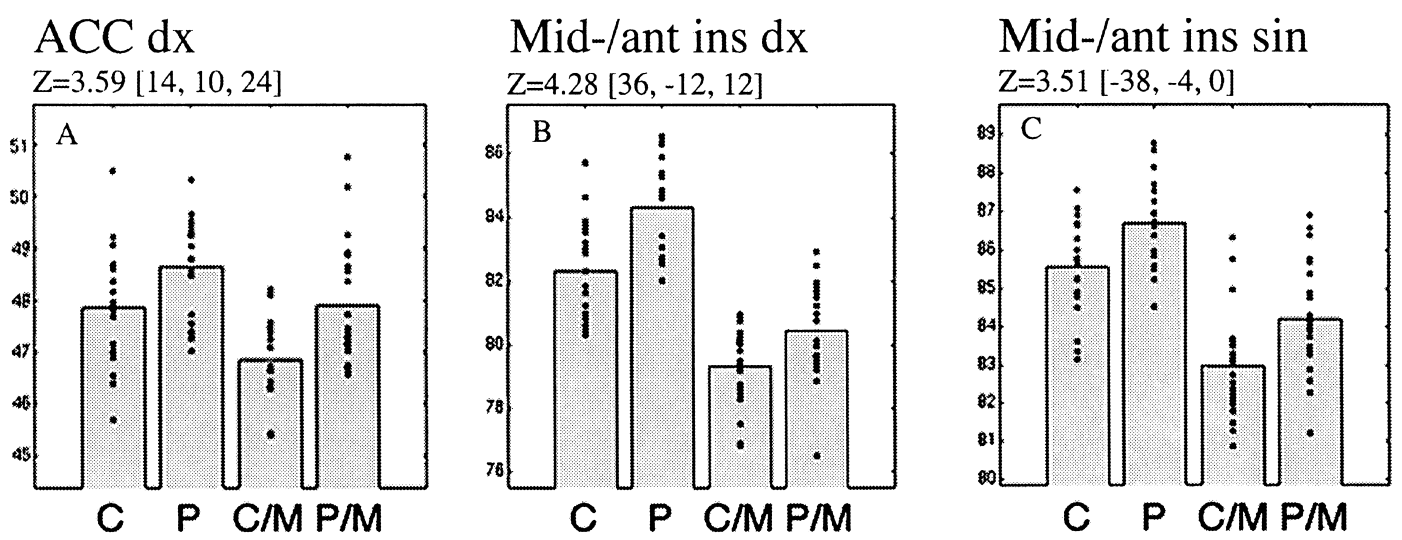

Fig. 3. Significant activations in the right ACC (A), the right mid-/anterior insula (B) and the left mid-/anterior insula (C) for the main effect of pain $[($ Pain + Pain/Maze $)-($ Cold + Cold/Maze $)]$. No significant interaction was observed in these regions. The data represents adjusted rCBF in the voxel with a $Z$-score maximum for the activated region. Each dot shows the $\mathrm{CBF}$ for each scan in the shown voxel. The bars show the average rCBF during the respective conditions. C, Cold; P, Pain; C/M, Cold/Maze; P/M, Pain/Maze. 


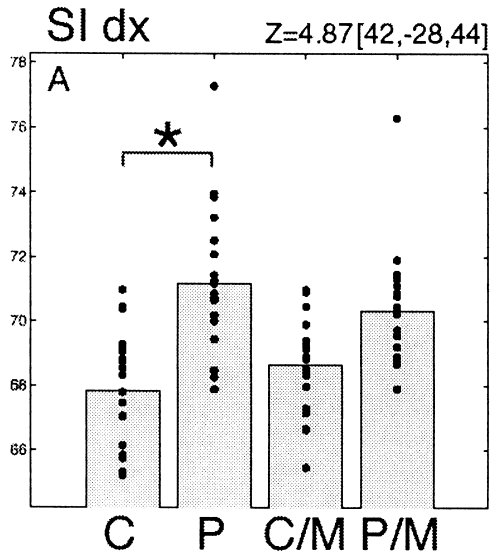

BA 47 si $z=3.78[-32,18,-16]$
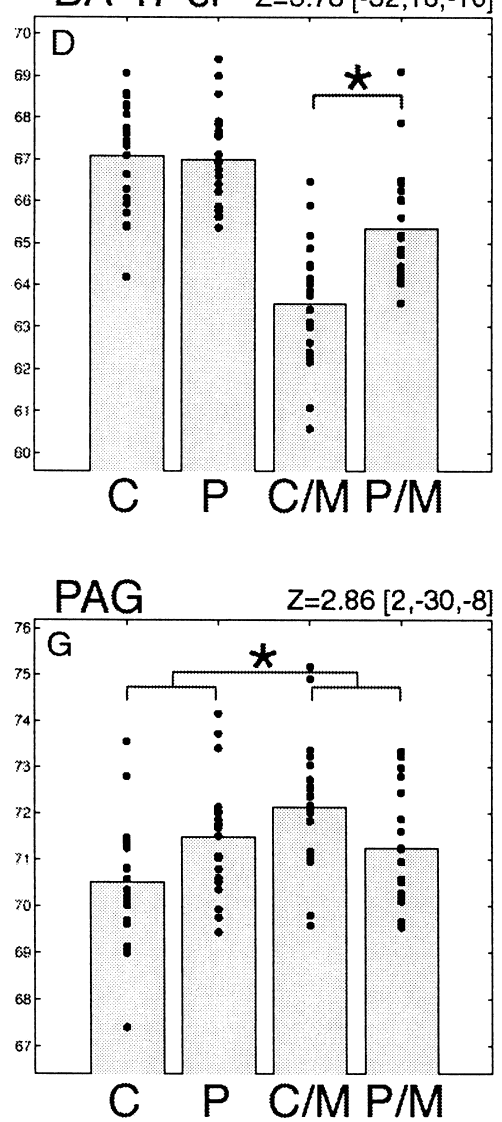

BA $43 \mathrm{dx} \quad \mathrm{z}=4.16[42,-16,16]$

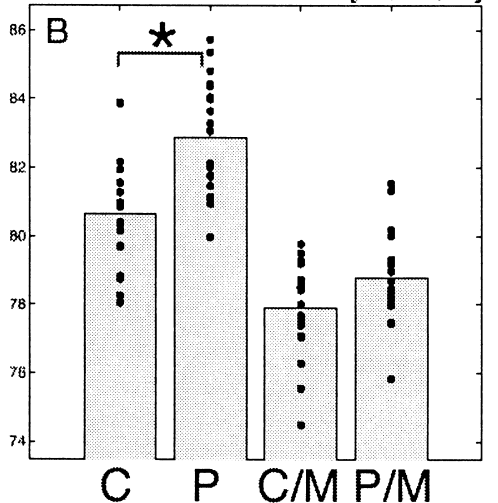

BA $43 d x \quad z=3.15[58,-14,20]$

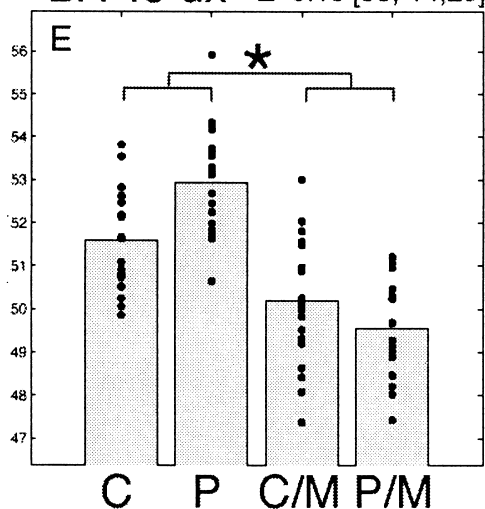

C $\mathrm{P}$ C/M P/M
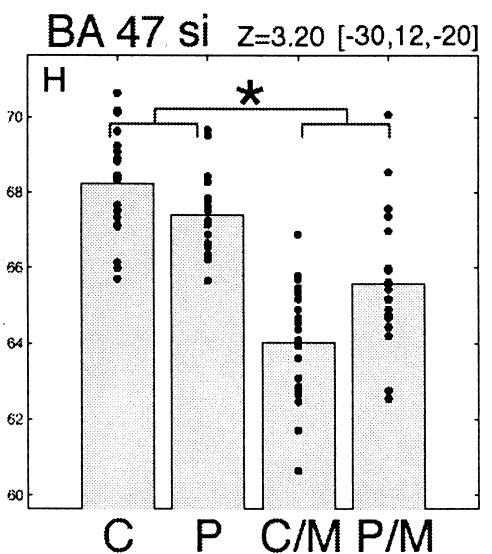

BA 43 si $z=4.50[-60,-12,20]$

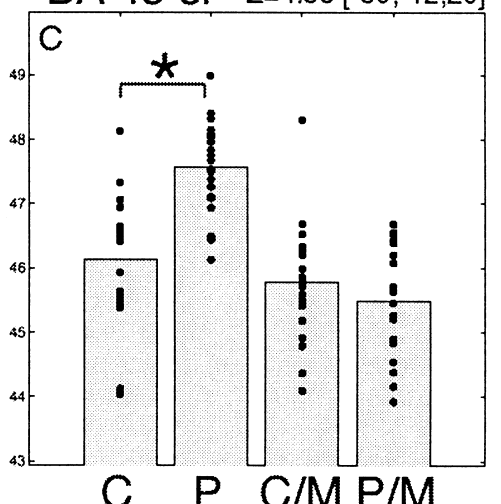

$Z=3.98$

BA 43/40/SI si $[-58,-14,24]$

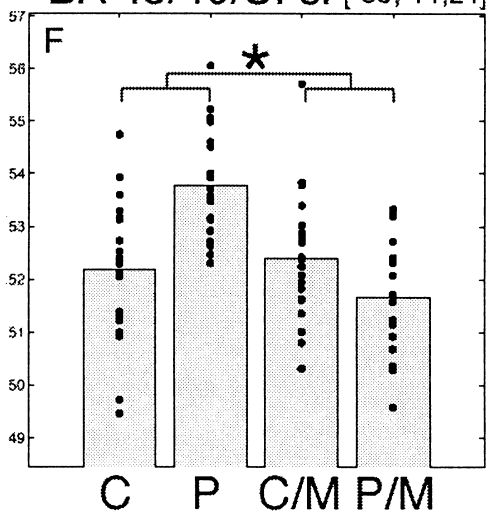

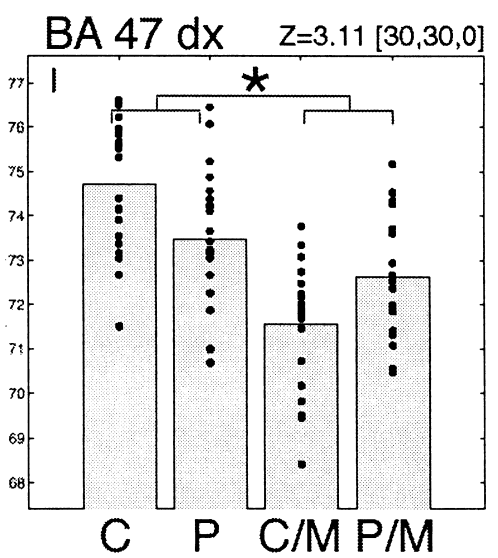

Fig. 4. Representative activations during Pain - Cold (A-C) and Pain/Maze - Cold/Maze (D). E-G shows significant interactions of (Pain - Cold) (Pain/Maze - Cold/Maze) and 4H,I shows significant interactions of (Pain/Maze - Cold/Maze) - (Pain - Cold). The data represents adjusted rCBF in the voxel with a $Z$-score maximum for the activated region. Each dot shows the $\mathrm{rCBF}$ for each scan in the shown voxel. The bars show the average rCBF during the respective conditions. C, Cold; P, Pain; C/M, Cold/Maze; P/M, Pain/Maze; S1, primary somatosensory cortex; PAG, periaqueductal gray; BA, Brodmann area.

as BA43 and inferior parts of BA40 include human homologue for $S 2$, area $7 b$ and retroinsula.

It has been proposed that the brain regions related to pain processing are divided into the medial pain system (ACC and mid-/anterior insula) processing affective-evaluative aspects of pain and the lateral pain system ( $\mathrm{S} 1$ and $\mathrm{S} 2$ ) processing sensory-discriminative aspects of pain (AlbeFessard et al., 1985; Vogt et al., 1993; Willis, 1995). Both of these pain systems were activated in the main effects contrast $[(\mathrm{P}+\mathrm{P} / \mathrm{M})-(\mathrm{C}+\mathrm{C} / \mathrm{M})]$. This is in accordance with a parallel processing of the affective-motivational and the sensory-discriminative dimensions of pain. However, incongruent results have been reported in several PETstudies of tonic pain for the lateral pain system. Somatotopic activations for the hand area in the primary somatosensory cortex have been observed in this and two other studies 


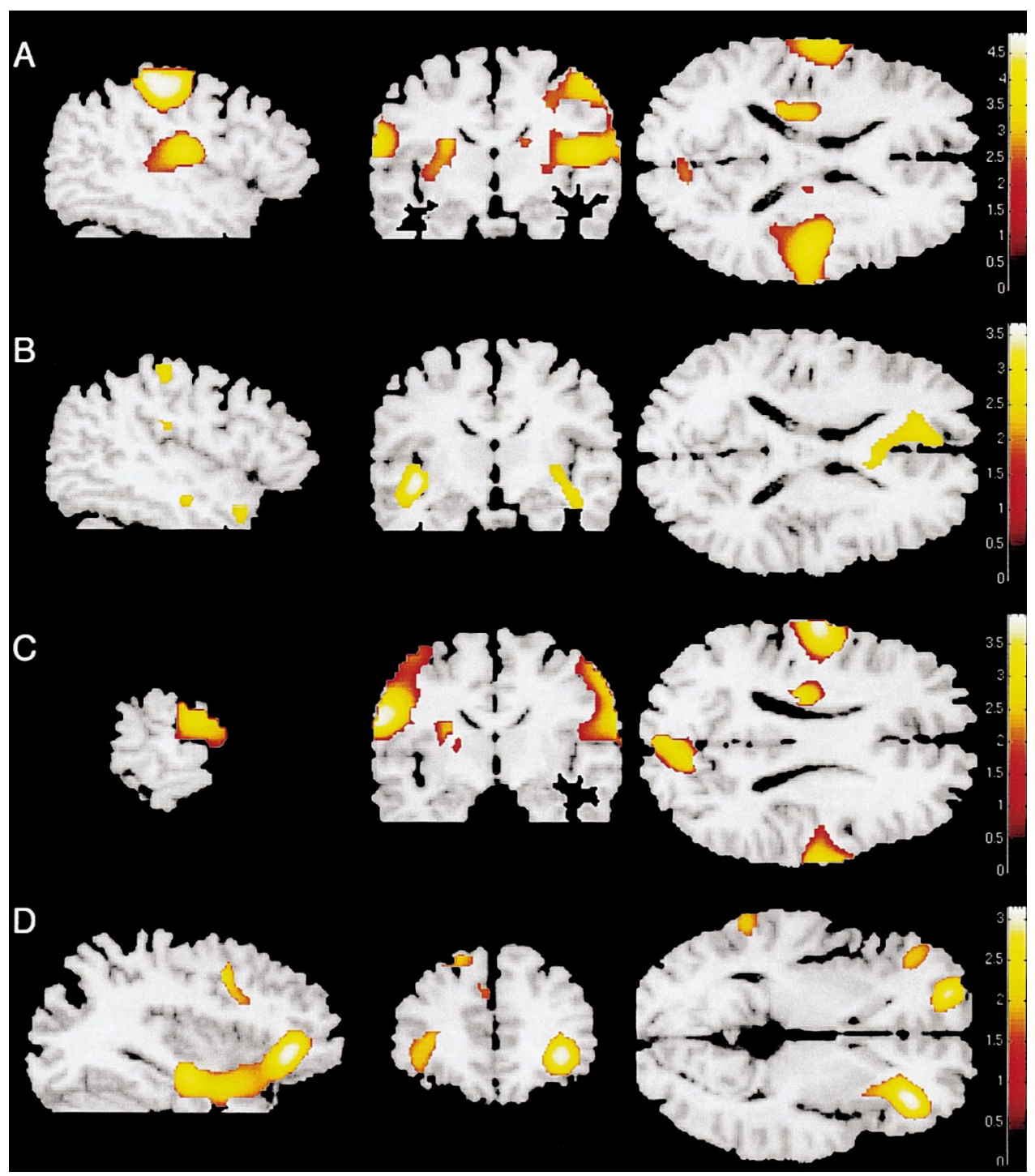

Fig. 5. Activations in the sensory association areas and S1 dx during Pain - Cold (A). These activations were not seen during Pain/Maze - Cold/Maze (B). C and D show significant interaction in BA43 dx and BA43/BA40/S1 sin during (Pain - Cold) - (Pain/Maze - Cold/Maze), and significant interaction in BA47 $\mathrm{dx}$ and BA47/11 sin during (Pain/Maze - Cold/Maze) - (Pain - Cold). A and B were thresholded at an uncorrected $P$-value $=0.01$. C and D were thresholded at an uncorrected $P$-value $=0.05$. The slices are shown in neurological convention, i.e. right is right and left is left in the coronal slices and the horizontal slices are shown from above. The sagittal slices are from the right hemisphere.

where the whole hand was immersed in painful hot or cold water (Casey et al., 1996; Rainville et al., 1997). However, Casey et al. (1996) reported no activation of S2 in the study of tonic cold pain. Further, no activation was observed in the lateral pain system in two studies of tonic heat pain applied to the volar forearm through a small aluminium plate (Adler et al., 1997; Gyulai et al., 1997). There may be several reasons for these discrepancies. The area of stimulation may be critical, i.e. the hand surface is larger than the area stimulated with the metallic plate $(2 \times 2 \mathrm{~cm}$ in the study of Gyulai et al., 1997). However, this does not fully explain the differences since phasic pain have often shown equally extensive activations in the lateral pain system as in the medial pain system, although the stimulated area was small. Studies of the autonomic responses and quantitative-
EEG (alpha-power) have suggested that tonic stimulation is biphasic with a dynamic change in the response after the first minute (Backonja et al., 1991; Tassorelli et al., 1995). Thus, the time window of the scan may be important in order to capture activations of the lateral pain system during experimental pain. In the studies where a clear increase was observed in both $\mathrm{S} 1$ and $\mathrm{S} 2$, stimulation started closer to the actual scanning thereby capturing the first part of the tonic painful stimulation. However, other factors such as arousal, anticipation and stimulation procedures may also be involved in altering the activity in the somatosensory regions.

The ACC was significantly activated during all pain scans vs. all non-pain scans although the maximum $\triangle \mathrm{rCBF}$ was lower than in the lateral pain system $(4.20 \%$ rCBF increase 
in $\mathrm{S} 1$ as compared to $1.94 \% \mathrm{rCBF}$ increase in $\mathrm{ACC})$. The low ratings of the painful stimulus may explain the observed lack of activation since the activation in the ACC is dependent of the level of the subjective pain sensation (Rainville et al., 1997). Coping strategies, which modulate the ACC activity, may develop during a pre-training session (Hsieh, 1995). Thus, the extensive pre-training may also have influenced the activity in the ACC. Similarly the mid-/anterior insula, that is also a part of the medial pain system, was significantly activated only in the main effect contrast for pain.

There was an increased activity in the ipsilateral somatosensory association areas. The peak activation was somewhat more anterior-lateral than the contralteral activation in BA40/43. A tendency of activation in the ipsilateral sensory association areas has previously been observed in one study involving noxious stimulus (Casey et al., 1994). Bilateral activation in these areas is also in accordance with physiological studies in primates (Robinson and Burton, 1980; Dong et al., 1989). Since the finding is at variance with some previous functional neuroimaging studies of pain it should be interpreted with some caution. Alternatively, it is possible that some motor activation, for example facial muscle tensions during pain may have contributed to this activation. However, we do not see this as a full explanation since the described motor activation from these muscle groups have been observed more anteriorly (at the same axial level) during pain (Casey et al., 1996; Hsieh, 1995; Svensson et al., 1997; Xu et al., 1997; Peyron et al., 1998). In addition, results from a fMRI study, have indicated several activations in the somatosensory association areas (S2), ranging from -8 to -28 in the $y$-axis and from the inner surface of the parietal operculum to the lateral surface of postcentral gurus (BA40/43) during non-painful somatosensory stimulation of the fingers (Gelnar et al., 1998). These borders are in good agreement with the coordinates of the peak activations due to pain and the peak interactions in this region observed in this study.

The main effect for the perceptual maze conditions reproduced the results of previous studies of this test (Ghatan et al., 1995; Ingvar et al., 1998). Thus, increased activity was observed in regions belonging to the visuospatial attention network and areas belonging to the ventral and dorsal visual stream suggesting a visual cognitive processing. Extensive deactivations were observed in regions processing nonvisual sensations and also in ventromedial/inferior prefrontal cortex suggesting a general functional inhibition of taskirrelevant processing during the Maze conditions.

The subjects were involved in solving the maze task by constantly pressing two keys with their right hand during the maze conditions. Since any movement may activate the postcentral gyrus and the sensory association areas (Weiller et al., 1996) there may be possible confounding activity in the somatosensory regions from the movement of the right hand. In agreement with studies of motor activity (Weiller et al., 1996) a sensorimotor activation contralaterally to the right hand was observed during the main effect of maze (Fig. 2B). However, there was no increase of activity in the postcentral gyrus contralateral to the painful/cold stimulation when the maze task was compared to rest $(\mathrm{C} / \mathrm{M}-\mathrm{C}$; Fig. 4A). Moreover, the activity was unchanged or even tended to decrease in BA43/BA40i bilaterally during $\mathrm{C} / \mathrm{M}-\mathrm{C}$ (Fig. 4B,C). Hence, there was no sign of increased activity due to the maze task per se in the somatosensory areas activated by the painful stimulation. Since these somatosensory regions are not activated during the maze task it is unlikely that the observed interaction is due to the maze task itself. Moreover, there was no observed behavioural difference in $\mathrm{C} / \mathrm{M}$ as compared to $\mathrm{P} / \mathrm{M}$ suggesting altered motor output and there was no interaction in the somatotopic S1area for the hand that executed the movement in order to solve the maze task. The unchanged or decreased activity in the relevant somatosensory association areas during the maze task is in line with previous studies of perceptual maze (Ghatan et al., 1995; Ingvar et al., 1998), but in contrast with simple movement which have shown increased activation in these regions (Weiller et al., 1996). The discrepancy may be due to an attentional shift from proprioception to the cognitive task and suggests that the activity due to movement is not simply additive in somatosensory areas.

\subsection{Interactions}

The subjects rated the pain intensity and pain unpleasantness significantly lower when the painful stimuli were presented during the attention-demanding task. Although the average difference in pain ratings between the two painful conditions was relatively small, all subjects also consequently reported that the pain intensity and unpleasantness was perceived less during $\mathrm{P} / \mathrm{M}$ than during $\mathrm{P}$ after each subgroup of scans containing each of the four conditions.

The neurophysiological correlate of the difference in pain perception was assessed by analysis of interaction. Three regions (see below) showed a relative larger activation in the pain-matrix during pain without the attentional task as compared to the activation during pain and the attentional task $[(\mathrm{P}-\mathrm{C})-(\mathrm{P} / \mathrm{M}-\mathrm{C} / \mathrm{M})]$.

Although we had hypothesised that the activity in the medial pain system, especially ACC would be altered as indicated by the interaction analysis no such findings were observed (Fig. 3A). The perceived unpleasantness of a painful stimulus is correlated to the activity in the ACC (Rainville et al., 1997) which is in line with findings that lesions in the human ACC may reduce the affective response of chronic ongoing pain (Ballantine et al., 1967; Vogt et al., 1993). The subjects rated the unpleasantness in painful stimulation less during simultaneous solving of the maze task. However, the overall ratings of pain unpleasantness were low and the difference between the two painful conditions were not as extensive as in the study by Rainville et al. (1997) where the pain unpleasantness was manipulated by 
Table 2

Coordinates of activations/deactivations in the orbitofrontal cortex during pain, altered mood and cognition in previous studies ${ }^{\mathrm{a}}$

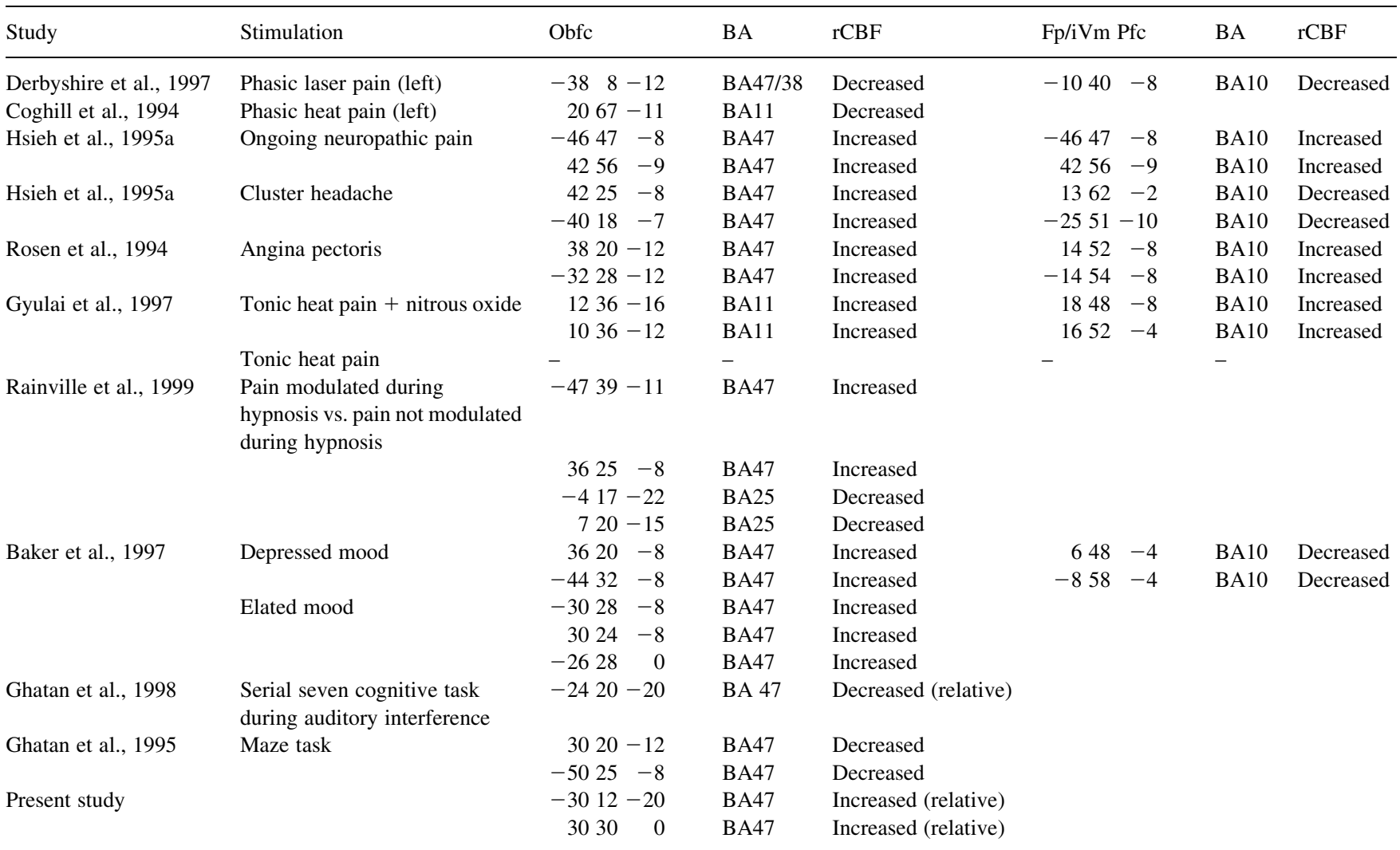

\footnotetext{
${ }^{\mathrm{a}}$ Obfc, Orbitofrontal cortex defined as BA47/11/25 in this study. Fp/iVm Pfc, frontopolar and inferior ventromedial prefrontal cortex. A negative $x$ coordinate denotes that the activation is in the left hemisphere and positive $x$-coordinate denotes the activation is in the right hemisphere.
}

the means of hypnosis. It has also been suggested that pretraining which includes the painful stimulus may induce coping strategies and may thereby alter the ACC response (Hsieh, 1995). These factors may have attenuated significant interaction effects in the ACC and the medial pain system. Another possible explanation for the lack of significant interaction in the ACC is that this region may have different roles during the different conditions, since the ACC also may be involved in the modulation of pain processing (Vogt et al., 1993) and in altered attentional demands. The opposing demands of the ACC activity, by reduced unpleasantness ratings combined with attentional as well as modulatory influences elicited by the ACC, may have resulted in an unchanged net effect of the activity in the region.

\subsubsection{Interactions in somatosensory association areas}

In the $(\mathrm{P}-\mathrm{C})$ condition activations were observed in the $\mathrm{S} 1$ and the somatosensory association areas as in the main effect for pain. In contrast, no significant activation was found here during $(\mathrm{P} / \mathrm{M}-\mathrm{C} / \mathrm{M})$. In the lateral parts of the somatosensory association areas (SAA) there was a significant interaction related to the observed differences. The interaction maximum in the contralateral right SAA (BA43) was located somewhat superior-lateral as compared to the peak in $(\mathrm{P}-\mathrm{C})$. The masking procedure indicated that the interaction maximum was part of the cluster of activated voxels in $(\mathrm{P}-\mathrm{C})$. Similarly, there was an interaction in the ipsilateral SAA. However, this interaction was even more superior, in-between BA40/43 and S1, and is therefore difficult to interpret.

Single neuron recordings in area $7 \mathrm{~b}$ and $\mathrm{S} 2$ have disclosed complex responses to somatotactile and noxious stimulation in primates (Robinson and Burton, 1980; Poranen and Hyvärinen, 1982). Activity in S2 neurons has shown dependence of attentional mechanisms, and activity in area $7 \mathrm{~b}$ has been demonstrated both as a result of noxious stimulation as well as presentation of the objects that previously have been associated with the noxious stimulation.

General modulations of somatosensory regions have previously been observed when somatotactile processing is serving as a potential distractor (Haxby et al., 1994; Shulman et al., 1997). Attentional modulations of the lateral pain system have also been observed during anticipation of painful and non-painful stimulation in functional imaging studies of humans (Drevets et al., 1995; Hsieh, 1995). The results of this study indicates that modulation of the somatosensory association system is present also during noxious stimulation in humans and may partly account for the lower pain ratings when presented with a concurrent distracting 
process. However, it is not possible to determine whether these noxious signals are modulated at the cortical or subcortical levels or both. These findings do not exclude modulations of the somatotopic area of the hand in the S1 where the interaction was below the level of significance.

\subsubsection{PAG/midbrain interaction}

Although the periaquiductal gray/midbrain was not significantly activated in the painful states there was a significant task by pain interaction in this structure. Increased activity in PAG/midbrain has been observed in several imaging studies of pain and interpreted as a part of the cerebral processing the nociceptive input (Casey et al., 1994; Rosen et al., 1994; Hsieh et al., 1995b; Petrovic et al., 1999). This is consistent with the tendency of the relative PAG rCBF increase in $(\mathrm{P}-\mathrm{C})$ as illustrated in the interaction analysis (Fig. 4G). In contrast, there was a relative decrease of activity in $\mathrm{PAG} /$ midbrain during $\mathrm{P} / \mathrm{M}$ as compared to $\mathrm{C} / \mathrm{M}$. We interpret this as a modulation of the pain related processing in the midbrain during cognitive distraction. PAG receives nociceptive input directly through spinal pathways (Blomqvist and Craig, 1991). The midbrain is also involved in the diffuse noxious inhibitory control (DNIC; (Villanueva and Le Bars, 1995)), and fight or flight defence reactions (Carrive, 1993). Thus, increased activity in $\mathrm{PAG} /$ midbrain during pain may represent processing of noxious input per se, behavioural response to pain and increased inhibition of the noxious input on a spinal level. A likely explanation is that the autonomic behaviour is modulated yielding a less intense defence reaction, which would otherwise interfere with the performance of the cognitive task. Alternatively, the processing of pain per se may be relatively inhibited during the concomitant cognitive task.

\subsubsection{Orbitofrontal interaction}

In the orbitofrontal cortex there was bilateral task by pain interactions in that the $\mathrm{rCBF}$ increased in the $\mathrm{P} / \mathrm{M}$ vs. $\mathrm{C} / \mathrm{M}$ and decreased in the $\mathrm{P}$ vs. C contrast (Fig. $4 \mathrm{H}, \mathrm{I}$ ).

The increase of activity in orbitofrontal regions during P/ $M$ could possibly be interpreted as an expression of altered neural processing to meet the increased cognitive demands when pain interfered with the maze task in order to solve the test. We deem this interpretation as less likely since the activity in lateral orbitofrontal cortex is decreased during maze task per se (Table 2; Ghatan et al., 1995) and there is an even stronger suppression of activity in BA47 when a cognitive task is interfered with an irrelevant distractor (Table 2; Ghatan et al., 1998). This suggests that the relative increase of activity in BA47 is coupled with the processing of pain during the cognitive task.

Previously, activations in the lateral orbitofrontal cortex have been shown during experimentally induced depressed or elated mood (Table 2; Pardo et al., 1993; Baker et al., 1997). This region has also been suggested to be involved in the modulation of distant functional systems during emotional states (Baker et al., 1997). Similarly, our data suggests that the interaction observed in the lateral orbitofrontal cortex might reflect higher-order modulatory activity of distant regions processing pain. Extensive activations in the lateral orbitofrontal region have previously been observed in spontaneous ongoing pain, cluster headache and in induced angina pectoris (Table 2; Rosen et al., 1994; Hsieh, 1995; Hsieh et al., 1995a). These studies represent clinical pain states with a highly relevant threat to the organism inducing altered mood and possible modulations of distant neural activity.

Why is there then a tendency of decreased activity in this region during $\mathrm{P}$ vs. C? One possible suggestion would be that this pattern of response is part of central mechanisms for coping with the pain stimulus. A coping strategy depends on how a subject evaluates threat (Lazarus, 1991). In the orbitofrontal cortex there are neurons responding to negative affective stimuli (Thorpe et al., 1983). Coping with a predictable pain stimulus may well include active modulation of the neural activity in this region. In support for this suggestion the activity in medial and lateral orbitofrontal cortex has been shown to decrease or to correlate negatively with the ratings of pain intensity in two studies of experimental pain (Table 2; Coghill et al., 1994; Derbyshire et al., 1997). This contrasts with studies of clinical pain. In the mentioned studies of Coghill and Derbyshire the subjects had participated in a practice session as in this study, which may have allowed for the development of coping strategies. During anticipation of a painful stimulation in subjects which had pre-training sessions including acquaintance with the painful stimulation the activity decreased in ventromedial/orbitofrontal cortex whereas subjects without any such training showed increased activity in the same regions during anticipation of an unpredictable painful stimulation (Hsieh, 1995). Thus, the study supports the suggestion that pre-training may modulate the activity of prefrontal regions (Hsieh, 1995). However, increased activity in orbitofrontal regions may be necessary to modulate distant interfering processing of pain during pain and additional cognitive load or during pain with a relevant threat to the organism.

The observed interaction in the orbitofrontal cortex is in line with the results of a previous PET study of the analgesic effects of nitrous oxide which showed a relative increase in orbitofrontal regions although the activity in the ACC was relatively decreased (Table 2; Gyulai et al., 1997). Also, the study of hypnotic modulation of pain perception (Rainville et al., 1997, 1999) shows results, which are in line with our data, i.e. there was a relative increase of activity in similar regions of BA47 when the pain perception was modulated in both studies (Table 2). However, the study of Rainville et al. (1999) also showed deactivations in more medial regions of orbitofrontal regions (BA25; Table 2) which suggests that different parts of the orbitofrontal regions may contribute differently during pain modulation.

The suggestion that the these regions may modulate 
distant processing of pain is supported by several animal studies showing that stimulation of lateral orbitofrontal cortex and ventromedial prefrontal cortex induces analgesic effects (Oleson et al., 1980; Hardy, 1985; Zhang et al., 1997). This effect is, at least partly, mediated by PAG, which may reflect the interaction of the activity in PAG/ midbrain observed in this study. The orbitofrontal cortex may not act directly on PAG. Although there are direct connections to the midbrain (Porrino and Goldman-Rakic, 1982), orbitofrontal cortex is also closely associated to insula, amygdala and ACC (Mufson and Mesulam, 1982; Vogt and Pandya 1987; Carmichael and Price, 1995) which also have possibilities of modulating the activity in PAG (LeDoux, 1993; Vogt et al., 1993; Mesulam, 1998).

\section{Conclusions}

We used a factorial experimental design to demonstrate an interaction between a painful stimulus and a cognitive task with great attentional demands. The data suggest an interaction in neural activation, which may relate to the decrease of the pain experience at the perceptual level when attention is actively directed away from a standard pain stimulus and towards an attentional and working memory-demanding cognitive task.

\section{Acknowledgements}

This work was supported by grants from the Swedish Medical Research Council (8276), the Karolinska Institute, the Swedish Medical Association and the Knut and Alice Wallenberg foundation and the Family Ekman Foundation Special thanks to Ellenor Andersson, Dennis Eriksson, Gustav von Heine, Göran Printz and Walter Pulka for technical and administrative support.

\section{References}

Adler LJ, Gyulai FE, Diehl DJ, Mintun MA, Winter PM, Firestone LL. Regional brain activity changes associated with fentanyl analgesia elucidated by positron emission tomography. Anasth Analg 1997;84:120-126.

Albe-Fessard D, Berkley KJ, Kruger L, Ralston HJ, Willis WD. Diencephalic mechanisms of pain sensation. Brain Res Rev 1985;9:217-296.

Andersson JLR, Lilja A, Hartvig P, Långström B, Gordh T, Handwerker H, Torebjörk E. Somatotopic organization along the central sulcus, for pain localization in humans, as revealed by positron emission tomography. Exp Brain Res 1997;117:192-199.

Apkarian AV. Functional imaging of pain: new insights regarding the role of the cerebral cortex in human pain perception. Semin Neurosci 1995; 7:279-293.

Backonja M, Howland EW, Wang J, Smith J, Salinsky M, Cleeland SC. Tonic changes in alpha power during immersion of the hand in cold water. Electroenceph clin Neurophysiol 1991;79:192-203.

Baker SC, Frith CD, Dolan RJ. The interaction between mood and cognitive function studied with PET. Psychol Med 1997;27:565-578.

Ballantine Jr HT, Cassidy WL, Flanagan NB, Marino Jr R. Stereotaxic anterior cingulotomy for neuropsychiatric illness and intractable pain. J Neurosurg 1967;26:488-495.

Bergström M, Boethius J, Eriksson L, Greitz T, Ribbe T, Widén L. Head fixation device for reproducible position alignment in transmission $\mathrm{CT}$ and positron emission tomography. J Comput Assist Tomogr 1981;5:136-141.

Berridge MS, Cassidy EH, Terris AH. A routine, automated synthesis of oxygen-15-labeled butanol for positron tomography. J Nucl Med 1990;31:1727-1731.

Blomqvist A, Craig AD. Organization of spinal and trigeminal input to the PAG. In: Depaulis A, Bandler R, editors. The midbrain periaqueductal gray matter: functional, anatomical and neurochemical organization, New York: Plenum Press, 1991. pp. 345-363.

Carmichael ST, Price JL. Limbic connections of the orbital and medial prefrontal cortex in macaque monkeys. J Comp Neurol 1995;363: 615-641.

Carrive P. The periaqueductal gray and defensive behaviour: functional representation and neuronal organization. Behav Brain Res 1993;58:27-47.

Casey KL, Minoshima S, Berger KL, Koeppe RA, Morrow TJ, Frey KA. Positron emission tomography analysis of cerebral structures activated specifically by repetitive noxious heat stimuli. J Neurophysiol 1994;71:802-807.

Casey KL, Minoshima S, Morrow TJ, Koeppe RA. Comparison of human cerebral activation patterns during cutaneous warmth, heat pain and deep cold pain. J Neurophysiol 1996;76:571-581.

Coghill RC, Talbot JD, Evans AC, Meyer E, Gjedde A, Bushnell MC, Duncan GH. Distributed processing of pain and vibration by the human brain. J Neurosci 1994;14:4095-4108.

Craig AD, Reiman EM, Evans A, Bushnell MC. Functional imaging of an illusion of pain. Nature 1996;384:258-260.

Davis KD, Taylor SJ, Crawley AP, Wood ML, Mikulis DJ. Functional MRI of pain- and attention-related activations in the human cingulate cortex. J Neurophysiol 1997;77:3370-3380.

Derbyshire SWG, Jones AKP, Gyulai F, Clark S, Townsend D, Firestone LL. Pain processing during three levels of noxious stimulation produces differential patterns of central activity. Pain 1997;73:431-445.

Dong WK, Salonen LD, Kawakami Y, Shiwaku T, Kaukoranta EM, Martin RF. Nociceptive responses of trigeminal neurons in $\mathrm{S} 2-7 \mathrm{~b}$ cortex of awake monkeys. Brain Res 1989;484:314-324.

Drevets WC, Burton H, Videen TO, Snyder AZ, Simpson JRJ, Raichle ME. Blood flow changes in human somatosensory cortex during anticipated stimulation. Nature 1995;373:249-252.

Elithorn A. Intelligence, perceptual integration and the minor hemisphere syndrome. Neuropsychologia 1964;2:327-332.

Friston KJ, Holmes AP, Worsley KJ, Poline J-P, Frackowiak RSJ. Statistical parametric maps in functional imaging: a general linear approach. Hum Brain Map 1995;2:189-210.

Gelnar PA, Krauss BR, Szeverenyi NM, Apkarian AV. Fingertip representation in the human somatosensory cortex: an fMRI study. Neuroimage 1998; 7:261-283.

Ghatan PH, Hsieh J-C, Wirsén-Meurling A, Wredling R, Eriksson L, StoneElander S, Levander S, Ingvar M. Brain activation induced by the perceptual maze test: a PET study of cognitive performance. Neuroimage 1995;2:112-124.

Ghatan PH, Hsieh JC, Petersson KM, Stone-Elander S, Ingvar M. Coexistence of attention-based facilitation and inhibition in the human cortex. Neuroimage 1998;7:23-29.

Gyulai FE, Firestone LL, Mintun MA, Winter PM. In vivo imaging of nitrous oxide-induced changes in cerebral activation during noxious heat stimuli. Anesthesiology 1997;86:538-548.

Hardy SGP. Analgesia elicited by prefrontal stimulation. Brain Res 1985;339:281-284.

Haxby JV, Horwitz B, Ungerleider LG, Maisog JM, Pietrini P, Grady CL. The functional organization of human extrastriate cortex: a PET-rCBF study of selective attention to faces and locations. J Neurosci 1994;14:6336-6353. 
Hodes RL, Howland EW, Lightfoot N, Cleeland CS. The effects of distraction on responses to cold pressor pain. Pain 1990;41:109-114.

Hsieh J-C. Thesis. Central processing of pain; functional brain imaging studies with PET, Stockholm: Karolinska Institute, 1995, Vol. ISBN:91-628-1722-1.

Hsieh J-C, Belfrage M, Stone-Elander S, Hansson P, Ingvar M. Central representation of chronic ongoing neuropathic pain studied by positron emission tomography. Pain 1995a;63:225-236.

Hsieh J-C, Ståhle-Bäckdahl M, Hägermark Ö, Stone-Elander S, Rosenqvist G, Ingvar M. Traumatic nociceptive pain activates the hypothalamus and the periaqueductal gray: a positron emission tomography study. Pain 1995b;64:303-314.

Iadarola MJ, Berman KF, Zeffiro TA, Byas-Smith MG, Gracely RH, Max MB, Bennett GJ. Neural activation during acute capsaicin-evoked pain and allodynia assessed with PET. Brain 1998;121:931-947.

Ingvar M, Eriksson L, Greitz T, Stone-Elander S, Dahlbom M, Rosenqvist G, af Trampe P, von Euler CV. Methodological aspects of brain activation studies: cerebral blood flow determined with $\left[{ }^{15} \mathrm{O}\right]$ butanol and positron emission tomography. J Cereb Blood Flow Metab 1994;14:628-638.

Ingvar M, Ghatan PH, Wirsén-Meurling A, Risberg J, von Heine G, StoneElander S, Ingvar DH. Alcohol activates the cerebral reward system in man. J Stud Alcohol 1998;59:258-269.

Jones AKP, Brown WD, Friston KJ, Qi LY, Frackowiak RSJ. Cortical and subcortical localization of response to pain in man using positron emission tomography. Proc R Soc Lond 1991;244:39-44.

Krubitzer L, Clarey J, Tweedale R, Elston G, Calford M. A redefinition of somatosensory areas in the lateral sulcus of macaque monkeys. J Neurosci 1995; 15:3821-3839.

Lazarus RS. Emotion and adaption, New York: Oxford, 1991. pp. 1-470.

LeDoux JE. Emotional memory systems in the brain. Behav Brain Res 1993;58:69-79.

Levander S. An automated psychological test battery, 1988.

Melzack R, Casey KL. Sensory, motivational and central control determinants of pain. In: Kenshalo DR, editor. The skin senses, Springfield, IL: CC Thomas, 1968. pp. 423-439.

Mesulam M-M. From sensation to cognition. Brain 1998;121:1013-1052.

Mesulam MM, Mufson EJ. The insula of reil in man and monkey. In: Peters A, Jones EG, editors. Cerebral cortex, Association and Auditory Cortex, vol. 4, New York: Plenum Press, 1985. pp. 179-226.

Mufson EJ, Mesulam M-M. Insula of the old world monkey. II: Afferent cortical input and comments on the claustrum. J Comp Neurol 1982;212:23-37.

Oleson TD, Kirkpatrick DB, Goodman SJ. Elevation of pain threshold to tooth shock by brain stimulation in primates. Brain Res 1980;194:7995.

Pardo JV, Pardo PJ, Raichle ME. Neural correlates of self-induced dysphoria. Am J Psychiatry 1993;150:713-719.

Petrovic P, Ingvar M, Stone-Elander S, Petersson K-M, Hansson P. a PET activation study of dynamic mechanical allodynia in patients with painful monneuropathy. Pain 1999;83:459-470.

Peyron R, Garcia-Larrea L, Grégoire MC, Convers P, Lavenne F, Veyre L, Froment JC, Mauguière F, Michel D, Laurent B. Allodynia after lateralmedullary (Wallenberg) infarct; a PET study. Brain 1998;121:345-356.

Poranen A, Hyvärinen J. Effects of attention on multiunit responses to vibration in the somatosensory regions of the monkey's brain. Electroenceph clin Neurophysiol 1982;53:525-537.

Porrino LJ, Goldman-Rakic PS. Brainstem innervation of prefrontal and anterior cingulate cortex in the rhesus monkey revealed by retrograde transport of HRP. J Comp Neurol 1982;205:63-76.

Rainville P, Duncan GH, Price DD, Carrier B, Bushnell MC. Pain affect encoded in human anterior cingulate but not somatosensory cortex. Science 1997;277:968-971.

Rainville P, Hofbauer RK, Paus T, Duncan GH, Bushnell MC, Price DD. Cerebral mechanisms of hypnotic induction and suggestion. J Cogn Neurosci 1999;11:110-125.

Rees G, Frith CD, Lavie N. Modulating irrelevant motion perception by varying attentional load in an unrelated task. Science 1997;278:16161619.

Roberts TS, Akert K. Insular and opercular cortex and its thalamic projection in Macaca mulatta. Schweiz Arch Neurol Neurochir Psychiatr 1963;92:1-43.

Robinson CJ, Burton H. Somatic submodality distribution within the second somatosensory (S2) 7b, retroinsular, postauditory, and granular insular cortical areas of M. fascicularis. J Comp Neurol 1980;192:93108.

Rosen SD, Paulesu E, Frith CD, Frackowiak RSJ, Davies GJ, Jones T, Camici PG. Central nervous pathways mediating angina pectoris. Lancet 1994;344:147-150.

Shulman GL, Corbetta M, Buckner RL, Raichle ME, Fiez JA, Miezin FM, Petersen SE. Top-down modulation of early sensory cortex. Cereb Cortex 1997;7:193-206.

Smith J, Jones D, Elithorn A. The perceptual maze. British Medical Research Council 1978;:1-21.

Svensson P, Minoshima S, Beydoun A, Morrow TJ, Casey KL. Cerebral processing of acute skin and muscle pain in humans. J Neurophysiol 1997;78:450-460.

Talairach J, Tournoux P. Co-planar stereotaxic atlas of the human brain, Stuttgart: George Thieme Verlag, 1988.

Talbot JD, Marrett S, Evans AC, Meyer E, Bushnell MC, Duncan GH. Multiple representations of pain in human cerebral cortex. Science 1991;25:1355-1358.

Tassorelli C, Micieli G, Osipova V, Rossi F, Nappi G. Pupillary and cardiovascular responses to the cold-pressor test. J Auton Nerv Syst 1995;55:45-49.

Thorpe SJ, Rolls ET, Maddison S. The orbitofrontal cortex: neuronal activity in the behaving monkey. Exp Brain Res 1983;49:93-115.

Villanueva L, Le Bars D. The activation of bulbo-spinal controls by peripheral nociceptive inputs: diffuse noxious inhibitory controls. Biol Res 1995;28:113-125.

Vogt BA, Pandya DN. Cingulate cortex of the rhesus monkey: II. Cortical afferents. J Comp Neurol 1987;262:271-289.

Vogt BA, Derbyshire S, Jones AKP. Pain processing in four regions of human cingulate cortex localized with co-registered PET and MR imaging. Eur J Neurosci 1996;8:1461-1473.

Vogt BA, Sikes RW, Vogt LJ. Anterior cingulate cortex and the medial pain system. In: Vogt BA, Gabriel M, editors. Neurobiology of cingulate cortex and limbic thalamus: a comprehensive handbook, Boston, MA: Birkhäuser, 1993. pp. 313-344.

Weiller C, Juptner M, Fellows S, Rijntjes M, Leonhardt G, Kiebel S, Muller S, Diener HC, Thilmann AF. Brain representation of active and passive movements. Neuroimage 1996;4:105-110.

Wienhard K, Dahlbom M, Eriksson L, Michel C, Bruckbauer T, Pietrzyk U, Heiss WD. The ECAT EXACT HR: performance of a new high resolution positron scanner. J Comput Assist Tomogr 1994;18:110-118.

Willis WDJ. Cold, pain and the brain. Nature 1995;373:19-20.

Xu X, Fukuyama H, Yazawa S, Mima T, Hanakawa T, Magata Y, Kanda M, Fujiwara N, Shindo K, Nagamine T, Shibasaki H. Functional localization of pain perception in the human brain studied by PET. NeuroReport 1997;8:555-559.

Zhang Y-Q, Tang J-S, Yuan B, Jia H. Inhibitory effects of electri-cally evoked activation of ventrolateral orbital cortex on the tail-flick reflex are mediated by periaqueductal gray in rats. Pain 1997;72:127-135. 